\title{
Neonatal outcomes of early- and late-onset preeclampsia
}

\author{
Melek Büyükeren ${ }^{1 \oplus}$, Hasan Tolga Çelik ${ }^{1 \oplus}$, Gökçen Örgül ${ }^{2 \oplus}$, Şule Yiğit ${ }^{1 \oplus}$, \\ M. Sinan Beksaç ${ }^{2 \oplus}$, Murat Yurdakök ${ }^{1 \oplus}$ \\ ${ }^{1}$ Division of Neonatology, Department of Pediatrics and ${ }^{2}$ Division of Perinatology, Department of Obstetrics and Gynecology, Hacettepe \\ University Faculty of Medicine, Ankara, Turkey.
}

\begin{abstract}
Background. The aim of the current study was to demonstrate the neonatal outcomes of infants born to mothers with early-onset preeclampsia (EP) and late-onset preeclampsia (LP), and compare the neonatal outcomes before and after 34 weeks of gestation in EP group.

Methods. In this retrospective study, we evaluated preeclamptic mother and child pairs who were followedup at Hacettepe University Hospital between the years 2010 and 2017. The pregnant women were classified as having EP if diagnosed before 34 weeks of gestation $(n=91)$ and LP if diagnosed after 34 weeks of gestation $(n=34)$. The women in the EP group were further divided into subgroups according to the gestational week at birth, including those who gave birth before 34 weeks of gestation (early birth; n=57) and after 34 weeks of gestation (late birth; $n=34$ ). Necessary clinical and demographic data were withdrawn from the electronic registry and patient files.
\end{abstract}

Results. Neonates in the EP/late birth subgroup had significantly lower gestational age and birthweight. Small for gestational age (SGA) frequency was higher in the early-onset subgroup born after 34 weeks' gestation compared to the late-onset preeclampsia group $(p=0,016)$. The incidence of neutropenia was significantly higher in the EP/late birth subgroup than in the LP group $(p=0.002)$. After correcting for gestational week and birth weight, neutrophil count was still significantly lower in the EP/late birth subgroup (p=0.002). EP/late birth subgroup and LP group had comparable outcomes regardless of neutrophil count and SGA rate.

Conclusions. Close follow up and postponing delivery in stable and appropriate pregnant women with preeclampsia would be beneficial for neonates.

Key words: newborn, early-onset preeclampsia, late-onset preeclampsia, neutropenia, small for gestational age.

Preeclampsia, an important cause of maternal morbidity and mortality, is a progressive multisystem disease characterized by the new onset of hypertension, proteinuria, or hypertension and end-organ dysfunction with or without proteinuria after 20 weeks of gestation. ${ }^{1,2}$ The incidence of preeclampsia in developing countries is about 3-5 per 100 live births. ${ }^{3,4}$

Preeclampsia is classified as early-onset or lateonset depending on whether it appears before

$\bowtie$ Melek Büyükeren

melekbuyukeren@hotmail.com

Received 13th November 2019,

accepted 29th November 2019. or after 34 weeks of gestation. ${ }^{5}$ In terms of its pathophysiology, early-onset preeclampsia (EP) is caused by intrinsic placental factors, whereas late-onset preeclampsia (LP) is attributed mainly to maternal factors. Thus, these two conditions are thought to be different conditions which have different etiological factors. ${ }^{6,7}$

The only treatment option for preeclampsia is delivery. Timing of birth depends on gestational week, maternal and fetal condition, and severity of the disease; so every patient should be evaluated individually. ${ }^{8}$ If mother and fetus are stable with no end-organ damage, delivery should be postponed as long as possible to enable fetal growth and maturation with close follow up. ${ }^{9}$ 
Preeclampsia results in preterm birth in $20 \%$ and intrauterine fetal growth restriction may be detected in $12 \%$ of cases. ${ }^{10}$ There are several complications such as intraventricular hemorrhage (IVH), respiratory distress syndrome (RDS), necrotizing enterocolitis (NEC), and retinopathy of prematurity (ROP) among premature infants of preeclamptic women. ${ }^{10,11}$ Moreover, studies showed that infants born to preeclamptic mothers have an increased risk of elevated blood pressure and high body mass index in childhood, also there is a nearly two-fold increase in the incidence of stroke in adulthood. ${ }^{12,13}$

We compared neonatal outcomes of infants born to mothers with EP and LP in this study. We also compared the outcomes of infants in early preeclamptic mothers regarding gestational week at delivery.

\section{Material and Methods}

In this retrospective study, we evaluated pregnant women who were followed up and delivered due to preeclampsia at Hacettepe Univerity Hospital between 2010 and 2017, and neonatal outcomes of these pregnancies were analyzed. The study protocol was approved by the Hacettepe Ethical Committee (GO 17/532). Initially, a total of 249 pairs of mothers and infants were identified by screening medical records. Two women with eclampsia, 37 women and 13 neonates with incomplete records or missing data, and 72 neonates with incomplete laboratory test results were excluded. The study was completed with the remaining 125 pairs of mother and infant.

The pregnant women were classified as having EP if diagnosed before 34 weeks of gestation $(n=91)$ and LP if diagnosed after 34 weeks of gestation $(n=34){ }^{2}$ The women in the EP group were further divided into subgroups, including those who gave birth before 34 weeks of gestation (early birth; $\mathrm{n}=57$ ) and after 34 weeks of gestation (late birth, $n=34$ ).
Antenatal corticosteroid therapy was defined as 2 doses of betamethasone ( $12 \mathrm{mg}$, intramuscular) at least $24 \mathrm{~h}$ before delivery. ${ }^{1}$ Abnormal ultrasonography was defined in the presence of absent or reversed end-diastolic flow in the umbilical artery on Doppler ultrasound examination. ${ }^{14}$ The neonates were assessed in the delivery room by a neonatologist and follow up was performed in the neonatal intensive care unit if necessary.

The subjects' demographic characteristics, gestational week at preeclampsia diagnosis, time interval between diagnosis and birth, maternal comorbidities, medication during pregnancy, and manner of delivery, as well as the neonates' gestational age at birth, Apgar score at $5^{\text {th }}$ minutes, neonatal findings, complete blood count values in the first $24 \mathrm{~h}$ after birth, length of hospital stay, and survival status were recorded. Neutropenia was defined as the absolute neutrophil count $\left(\right.$ ANC) $<1500 / \mu \mathrm{L} .{ }^{15}$

\section{Statistical analysis}

Statistical analyses were performed using IBM SPSS software. The variables with a normal distribution were evaluated with an independent samples t-test, and the variables not conforming to a normal distribution were analyzed using the nonparametric MannWhitney $\mathrm{U}$ test. $\mathrm{P}$ values less than 0.05 were considered statistically significant. Categorical variables were analyzed using Fisher's exact and Pearson's chi-square tests. The results were expressed as the median and $25^{\text {th }}-75^{\text {th }}$ quartile values. Analysis of covariance was used to correct for gestational week and birth weight.

\section{Results}

Among the 125 neonates in the study, 91 were in the EP group and 34 in the LP group. The mean gestational age at birth was $33.5 \pm 3.8$ (22.6-40.0) weeks, and the mean birth weight was $1987 \pm 984$ (480-4750) g. Comparison of the demographic and neonatal characteristics of the pregnant women and infants are shown in Tables I and II. 
Table I. Demographic characteristics of the patients.

\begin{tabular}{lcccc}
\hline Characteristic & $\begin{array}{c}\text { Early-onset } \\
\text { preeclampsia }(\mathrm{n}=91)\end{array}$ & $\begin{array}{c}\text { Late-onset } \\
\text { preeclampsia }(\mathrm{n}=34)\end{array}$ & $\begin{array}{c}\text { Total } \\
\mathrm{n}=125\end{array}$ & $\mathrm{p}$ \\
\hline Sex (Male/Female) & $46 / 45$ & $21 / 13$ & $67 / 58$ & 0.316 \\
$\mathrm{n} / \mathrm{n}(\% / \%)$ & $(50.5 / 49.5)$ & $(61.8 / 38.2)$ & $(53.6 / 46.4)$ & \\
Gestational week * & $32.6(30.0-34.6)$ & $37.7(36.7-38.4)$ & $34.4(31.1-36.7)$ & $<0.001$ \\
Birth weight (g) & $1540(960-1920)$ & $3135(2850-3440)$ & $1800(1160-2850)$ & $<0.001$ \\
ART, $\mathrm{n}(\%)$ & $18(19.8)$ & $2(5.9)$ & $20(16.0)$ & 0.097 \\
Corticosteroid administration, n (\%) & $62(68.1)$ & $3(8.8)$ & $65(52.0)$ & $<0.001$ \\
Abnormal Doppler, n (\%) & $12(13.2)$ & $2(5.9)$ & $14(11.2)$ & 0.347 \\
CS / VD n/n (\%/\%) & $87 / 4(95.6 / 4.4)$ & $33 / 1(97.1 / 2.9)$ & $120 / 5(96.0 / 4.0)$ & 1.000 \\
Apgar at 5th min & $9(7-10)$ & $10(10-10)$ & $9(8-10)$ & $<0.001$ \\
Need for resuscitation at birth, $\mathrm{n}(\%)$ & $40(44.0)$ & $1(2.9)$ & $41(32.8)$ & $<0.001$ \\
SGA, $\mathrm{n}(\%)$ & $43(47.3)$ & $0(0.0)$ & $43(34.4)$ & $<0.001$ \\
\hline
\end{tabular}

${ }^{*}$ median $\left(25^{\text {th }}-75^{\text {th }}\right.$ percentile); ART: assisted reproductive technique; CS: cesarean section; VD: vaginal delivery;

SGA: small for gestational age.

Table II. Neonatal characteristics of the patients.

\begin{tabular}{lcccc}
\hline Characteristic & $\begin{array}{c}\text { Early-onset } \\
\text { preeclampsia }(\mathrm{n}=91)\end{array}$ & $\begin{array}{c}\text { Late-onset } \\
\text { preeclampsia }(\mathrm{n}=34)\end{array}$ & $\begin{array}{c}\text { Total } \\
\mathrm{n}=125\end{array}$ & $\mathrm{p}$ \\
\hline MV duration (days) & $5(2-10.5)$ & - & - & - \\
RDS, $\mathrm{n}(\%)$ & $31(34.1)$ & $1(2.9)$ & $32(25.6)$ & $<0.001$ \\
TPN duration (days) & $10(4-18)$ & - & - & - \\
Hospital stay (days) & $10.0(5.0-26.0)$ & $2.0(2.0-2.0)$ & $6.0(2.0-17.0)$ & $<0.001$ \\
Gestational age at diagnosis of & $30.0(27.8-32.0)$ & $37.0(36.0-37.7)$ & $32.0(28.8-35.0)$ & $<0.001$ \\
preeclampsia (weeks)* & & & & \\
Time interval between diagnosis and & $14(1-28)$ & $0(0-6)$ & $7(0-22)$ & $<0.001$ \\
birth (days) & $16(17.6)$ & $1(2.9)$ & $17(13.6)$ & 0.039 \\
Neonatal pneumonia, $\mathrm{n}(\%)$ & $6(6.6)$ & 0 & $6(4.8)$ & 0.188 \\
IVH, $\mathrm{n}(\%)$ & $4(4.4)$ & 0 & $4(3.2)$ & 0.574 \\
Pneumothorax, $\mathrm{n}(\%)$ & $15(16.5)$ & 0 & $15(12.0)$ & 0.011 \\
PDA, $\mathrm{n}(\%)$ & $24(26.4)$ & 0 & $24(19.2)$ & $<0.001$ \\
Sepsis, $\mathrm{n}(\%)$ & $18(19.8)$ & 0 & $18(14.4)$ & 0.003 \\
NEC, $\mathrm{n}(\%)$ & $4(4.4)$ & 0 & $4(3.2)$ & 0.574 \\
ROP, $\mathrm{n}(\%)$ & $10(11.0)$ & 0 & $10(8.0)$ & 0.061 \\
BPD, $\mathrm{n}(\%)$ & $2(2.2)$ & 0 & $2(1.6)$ & 1.000 \\
Apnea, $\mathrm{n}(\%)$ & $12(13.2)$ & 0 & $12(9.6)$ & 0.035 \\
Death, $\mathrm{n}(\%)$ & & 0 &
\end{tabular}

${ }^{*}$ median $\left(25^{\text {th }}-75^{\text {th }}\right.$ percentile); MV: mechanical ventilation (intubation); RDS: respiratory distress syndrome; TPN: total parenteral nutrition; IVH: intraventricular hemorrhage; PDA: patent ductus arteriosus; NEC: necrotizing enterocolitis; ROP: retinopathy of prematurity; BPD: bronchopulmonary dysplasia.

No statistically significant differences were found between the EP and LP groups with regard to neonatal gender, use of assisted reproductive techniques, abnormal Doppler findings, manner of delivery, incidence of pneumothorax, ROP (> Grade I), BPD (defined as oxygen requirement either at 28 postnatal days or 36 weeks postmenstrual age), IVH (> 
Grade I), and apnea $(\mathrm{p}=0.316 ; \mathrm{p}=0.097 ; \mathrm{p}=0.347$; $p=1.000 ; p=0.574 ; p=0.574 ; p=0.061 ; p=0.188$; $\mathrm{p}=1.000$, respectively).

The EP group had a significantly lower gestational age at the time of diagnosis, gestational age at birth, birth weight, and $5^{\text {th }}$ min Apgar score compared to the LP group ( $p$ $<0.001$ for all). Neonates in the EP group had a significantly longer hospital stay and time interval between diagnosis and birth; as well as a significantly higher rate of steroid therapy, need for resuscitation, SGA, pneumonia, PDA, sepsis (proven sepsis), NEC ( $>$ Grade I), RDS, and mortality $(\mathrm{p}<0.001 ; \mathrm{p}<0.001 ; \mathrm{p}<0.001 ; \mathrm{p}<$ $0.001 ; p<0.001 ; p=0.039 ; p=0.011 ; p<0.001 ; p=$ $0.003 ; \mathrm{p}<0.001 ; \mathrm{p}=0.035$, respectively).

The comparison of neonatal complete blood count values in the first 24 hours after birth in infants in the EP and LP groups is shown in Table III.

Hemoglobin, hematocrit, white blood cell, thrombocyte, and neutrophil counts were significantly lower in the EP group compared to the LP group ( $\mathrm{p}<0.001 ; \mathrm{p}<0.001 ; \mathrm{p}=0.003$; $\mathrm{p}=0.011 ; \mathrm{p}<0.001$, respectively). The incidence of neutropenia was $24.2 \%$ in the EP group and $8.8 \%$ in the LP group, but the difference was not statistically significant $(p=0.078)$.

A comparison of infants in the LP group $(n=34)$ and those in the EP group that were delivered after 34 weeks of gestation ( $n=$ 34) is presented in Table IV. The neonates in the EP/late birth subgroup had significantly lower gestational age and birth weight $(\mathrm{p}<$ $0.001 ; \mathrm{p}<0.001$, respectively). However, no statistically significant differences were found between these two groups in terms of gender, abnormal Doppler, manner of delivery, need for resuscitation, or rates of RDS, pneumonia, pneumothorax, and mortality $(p=0.806 ; p=$ 0.493; $\mathrm{p}=1.000 ; \mathrm{p}=0.197 ; \mathrm{p}=1.000 ; \mathrm{p}=1.000 ; \mathrm{p}=$ $1.000 ; p=1.000$, respectively) (Table IV).

In the EP/late birth group, use of assisted reproductive techniques, antenatal steroid therapy, and SGA status were significantly more common, and hospital stay and time between preeclampsia diagnosis and delivery were significantly longer than in the LP group $(p=0.045 ; p<0.001 ; p<0.001 ; p<0.001 ; p<0.001$, respectively). The Apgar score was higher in the LP group $(p=0.016)$ (Table IV).

Table V shows the comparison of the complete blood count values in the first $24 \mathrm{~h}$ after birth between neonates in the EP group born after 34 weeks of gestation and infants in the LP group.

The comparison of complete blood count values in the first $24 \mathrm{~h}$ after birth between EP infants born after 34 weeks of gestation and LP infants revealed no statistical differences in hemoglobin or hematocrit $(p=0.076 ; p=0.053$, respectively), but white blood cell, thrombocyte, and neutrophil counts were significantly lower in the EP group $(p=0.039 ; p=0.008 ; p=0.001$, respectively). The incidence of neutropenia was significantly higher in the EP/late birth

Table III. Hematologic parameters of infants born to mothers with early-onset and late-onset preeclampsia.

\begin{tabular}{lccc}
\hline Complete blood count values & $\begin{array}{c}\text { Early-onset preeclampsia } \\
(\mathrm{n}=91)\end{array}$ & $\begin{array}{c}\text { Late-onset preeclampsia } \\
(\mathrm{n}=34)\end{array}$ & $\mathrm{p}$ \\
\hline Hemoglobin $(\mathrm{g} / \mathrm{dl})^{*}$ & $16.3(15.1-18.5)$ & $18.6(17.0-20.4)$ & $<0.001$ \\
Hematocrit $(\%)^{*}$ & $50.2(45.8-54.6)$ & $55.7(52.2-61.3)$ & $<0.001$ \\
White blood cell count $\left(/ \mathrm{mm}^{3}\right)^{*}$ & $10000(5500-14400)$ & $12700(10200-16800)$ & 0.003 \\
Thrombocyte count $\left(/ \mathrm{mm}^{3}\right)^{*}$ & $164000(106000-219000)$ & $212500(156000-256000)$ & 0.011 \\
Neutrophil count $\left(/ \mathrm{mm}^{3}\right)^{*}$ & $2200(1150-6050)$ & $8050(5400-12100)$ & $<0.001$ \\
Neutropenia, $\mathrm{n}(\%)$ & $31(34.1 \%)$ & $3(8.8 \%)$ & 0.006 \\
\hline
\end{tabular}

*Median $\left(25^{\text {th }}-75^{\text {th }}\right.$ percentile); Neutropenia=absolute neutrophil count $<1500 \mathrm{~mm}^{3}$. 
subgroup than in the LP group $(\mathrm{p}=0.002)$. After correcting for gestational week and birth weight, neutrophil count was still significantly lower in the EP/late birth subgroup ( $\mathrm{p}=0.002)$, and no differences were observed in the other hematological parameters.

Table IV. Comparison of infants in the early-onset preeclampsia group born after 34 weeks of gestation and infants in the late-onset preeclampsia group.

\begin{tabular}{|c|c|c|c|}
\hline Characteristic & $\begin{array}{l}\text { Early-onset preeclampsia }+ \\
\quad \text { late birth }(\mathrm{n}=34)\end{array}$ & $\begin{array}{l}\text { Late-onset preeclampsia } \\
\qquad(\mathrm{n}=34)\end{array}$ & $\mathrm{p}$ \\
\hline Gender (Male/Female) & $19 / 15$ & $21 / 13$ & 0.806 \\
\hline $\mathrm{n} / \mathrm{n}(\% / \%)$ & $(55.9 / 44.1)$ & $(61.8 / 38.2)$ & \\
\hline Gestational age (weeks)* & $34.9(34.4-36.2)$ & $37.7(36.7-38.4)$ & $<0.001$ \\
\hline Birth weight $(\mathrm{g})^{*}$ & $1980(1740-2380)$ & $3135(2850-3440)$ & $<0.001$ \\
\hline $\mathrm{ART}, \mathrm{n}(\%)$ & $9(26.5)$ & $2(5.9)$ & 0.045 \\
\hline Intrauterine steroid therapy, $\mathrm{n}(\%)$ & $32(94.1)$ & $3(8.8)$ & $<0.001$ \\
\hline Abnormal Doppler, n (\%) & 0 & $2(5.9)$ & 0.493 \\
\hline CS/NSVD, n/n (\%/\%) & $32 / 2(94.1 / 5.9)$ & $33 / 1(97.1 / 2.9)$ & 1.000 \\
\hline Apgar at 5 th $\min ^{*}$ & $10(8-10)$ & $10(10-10)$ & 0.016 \\
\hline Need for resuscitation at birth, $\mathrm{n}(\%)$ & $5(14.7)$ & $1(2.9)$ & 0.197 \\
\hline MV duration (days)* & $2(2-3)$ & - & - \\
\hline RDS, n (\%) & $1(2.9)$ & $1(2.9)$ & 1.000 \\
\hline TPN duration (days)* & $4(3-8)$ & - & - \\
\hline Hospital stay (days)* & $6(2-10)$ & $2(2-2)$ & $<0.001$ \\
\hline $\begin{array}{l}\text { Gestational age at preeclampsia diagnosis } \\
\text { (weeks)* }\end{array}$ & $32.0(29.0-33.0)$ & $37.0(36.0-37.7)$ & $<0.001$ \\
\hline Time between diagnosis and birth (weeks) & $4.0(2.7-5.9)$ & $0.0(0.0-0.9)$ & $<0.001$ \\
\hline SGA, n (\%) & $17(50.0)$ & $0(0.0)$ & $<0.001$ \\
\hline Pneumonia, n (\%) & $1(2.9)$ & $1(2.9)$ & 1.000 \\
\hline Pneumothorax, n (\%) & $1(2.9)$ & 0 & 1.000 \\
\hline Death, n (\%) & $1(2.9)$ & 0 & 1.000 \\
\hline
\end{tabular}

*median $\left(25^{\text {th }}-75^{\text {th }}\right.$ percentile); ART: assisted reproductive technique; CS: cesarean section; NSVD: normal spontaneous vaginal delivery; MV: mechanical ventilation (intubation); RDS: respiratory distress syndrome; TPN: total parenteral nutrition; SGA: small for gestational age.

Table V. Hematological parameters of infants of mothers with early-onset preeclampsia born after 34 weeks of gestation and neonates of mothers with late-onset preeclampsia.

\begin{tabular}{lcccc}
\hline Complete blood count values & $\begin{array}{c}\text { Early-onset } \\
\text { preeclampsia + late } \\
\text { birth }(\mathrm{n}=34)\end{array}$ & $\begin{array}{c}\text { Late-onset } \\
\text { preeclampsia }(\mathrm{n}=34)\end{array}$ & $\mathrm{p}$ & $\mathrm{p}_{\mathrm{s}}$ \\
\hline Hemoglobin $(\mathrm{g} / \mathrm{dl})^{*}$ & $17.3(15.6-19.2)$ & $18.6(17.0-20.4)$ & 0.076 & 0.307 \\
Hematocrit $(\%)^{*}$ & $52.1(50.1-58.7)$ & $55.7(52.2-61.3)$ & 0.053 & 0.371 \\
WBC $(/ \mathrm{mm} 3)^{*}$ & $10400(7300-15700)$ & $12700(10200-16800)$ & 0.039 & 0.918 \\
Thrombocyte count $(/ \mathrm{mm} 3)^{*}$ & $149000(103000-$ & $212500(156000-$ & 0.008 & 0.083 \\
Neutrophil count $(/ \mathrm{mm} 3)^{*}$ & $212000)$ & $256000)$ & & 0.002 \\
Neutropenia, $\mathrm{n}(\%)$ & $1600(1000-4500)$ & $8050(5400-12100)$ & $<0.001$ & - \\
\hline
\end{tabular}

*Median $\left(25^{\text {th }}-75^{\text {th }}\right.$ percentile); Neutropenia=absolute neutrophil count $<1500 \mathrm{~mm}^{3} ; \mathrm{p}_{\mathrm{s}}: \mathrm{p}$ value calculated after correcting for gestational age and birth weight 


\section{Discussion}

The early onset of preeclampsia is associated with increased risk of life-threatening maternal complications and fetal death, whereas late onset preeclampsia is usually associated with minor placental involvement and a milder clinical presentation. ${ }^{7}$ In addition, EP is associated with lower gestational age at birth, thus preterm birth complications are also more common in this group. Although previous studies compared hematological and neonatal features in EP and $\mathrm{LP}^{16-18}$ to the best of our knowledge, ours is the first study in the literature to compare these variables in neonates born to mothers with LP and neonates of mothers with EP born after 34 weeks of gestation.

As our hospital is a tertiary care center that receives referrals of high risk pregnancies, more patients were presented in the EP group. Consequently, median gestational age at birth and birth weight were lower in the EP group than in the LP group (median, $25^{\text {th }}-75^{\text {th }}$ percentile: 32.6 , 30.0-34.6 weeks vs. $37.7,36.7-$ 38.4 weeks; $1540,960-1920 \mathrm{~g}$ vs. 3135, 2850-3440 $\mathrm{g}$, respectively). Nevertheless, we repeated the statistical comparisons after correcting for these differences in gestational age and birth weight.

Neonatal morbidity and mortality risk is higher with decreasing gestational age and birth weight. Besides prematurity and low birth weight, complications such as IVH and BPD are other factors that increase the risk of morbidity, particularly neurodevelopmental delays, in preterm infants. ${ }^{19}$ In our study, the EP group had higher rates of neonatal morbidities (RDS, NEC, sepsis, PDA, and pneumonia), placental insufficiency findings (abnormal Doppler ultrasonography), SGA, lower Apgar scores, need for resuscitation, longer hospital stay, and mortality rate. These findings support the higher risk in preterm infants of mothers with EP than in those with LP.

These results are somewhat expected for preterm infants with lower gestational age and birth weight. However, neonatal risks can be further reduced, especially in women with EP, by carefully planning delivery time with close prenatal follow-up in a tertiary center with an experienced team consisting of perinatologists and neonatologists. Similar to the study of $\mathrm{Ni}$ et al. $^{17}$ we observed no significant difference in the incidence of IVH between the EP and LP groups. However, studies including larger sample numbers and analyses of long-term neurodevelopmental follow-up data are still needed.

A higher prevalence of abnormal Doppler findings in the uterine artery was reported in EP in some studies, ${ }^{7,20}$ but no such difference was observed between the EP and LP groups in our study ( $p=0.347)$. However, abnormal uterine artery Doppler findings are strong indicators of placental deficiency; they may not be a direct indicator of preeclampsia-related placental deficiency, chronic intrauterine hypoxia, or fetal growth restriction. In our study, the SGA rate was higher in the EP group $(\mathrm{p}<0.001)$. Madazli et al. ${ }^{7}$ evaluated 154 pregnant women, 91 (59\%) with EP and 63 (41\%) with LP, and reported that although no statistical differences were found between the EP and LP groups, the EP group had higher SGA frequency and lower Apgar score and mortality rates. Iacobelli et al. ${ }^{18}$ reported no statistical difference between infants born to mothers with EP and LP in terms of the first min. Apgar score and SGA rate after correcting for gestational age. Our findings are compatible with the literature; however comparison of EP/late birth subgroup and LP group was not available in those studies. Moreover, hematological parameters of the neonates born to preeclamptic mothers were also investigated in our study.

In our study, gestational age and birth weight were significantly lower in neonates of EP mothers born after 34 weeks of gestation $(n=34)$ than in those of LP mothers $(n=34)(p<0.001$; $p<0.001$, respectively). SGA frequency and $5^{\text {th }}$ min Apgar scores were significantly higher in the EP group ( $p=0.016 ; p<0.001$, respectively). However, neonatal morbidity and mortality rates were significantly lower in EP infants 
born after 34 weeks of gestation. This finding shows that, pregnant women diagnosed with EP should be closely followed up, and delivery should be scheduled after 34 weeks whenever possible to reduce the neonatal morbidity and mortality.

Our results show that infants of EP mothers born at gestational ages over 34 weeks had comparable hemoglobin and hematocrit values with infants born to mothers with LP. Although we expected these values to be lower in the EP group because of their lower mean gestational age and birth weight, we believe that the similar values in the two groups could be attributable to the EP infants having increased erythropoiesis secondary to the higher rate of SGA. ${ }^{20}$

There are some studies which investigated the hematological parameters in infants of preeclamptic mothers in the literature, ${ }^{22-23}$ only a small number of studies have compared the hematological parameters in babies born to mothers with EP and LP. ${ }^{16}$ Herzog et al. ${ }^{16}$ analyzed the complete blood count data from the cord blood of infants born to $11 \mathrm{EP}$ and $12 \mathrm{LP}$ mothers and found that leukocyte, neutrophil, and thrombocyte counts were significantly lower in the EP group. The median gestational age and birth weight were 31.0 weeks and 1155 $\mathrm{g}$ in the EP group and 37.4 weeks and $3238 \mathrm{~g}$ in the LP group, respectively. After correcting for gestational age and birth weight, only reduced neutrophil count was significantly associated with EP. ${ }^{16}$ Similarly, we found that white blood cell, thrombocyte, and neutrophil counts were significantly lower in the EP group $(p=0.039 ; p=$ $0.008 ; p=0.001$, respectively). The incidence of neutropenia was higher in the EP subgroup born after 34 weeks of gestation than in the LP group $(p=0.002)$. After correcting for gestational week and birth weight, neutrophil count remained significantly lower in the EP/late birth subgroup $(p=0.002)$, and no differences were observed in the other hematological parameters.

To the best of our knowledge previous studies compared only EP and LP groups, ${ }^{17-18}$ whereas we also compared neonatal and hematological outcomes between EP and LP infants and also EP/late birth and LP. The limitations of our study include the retrospective design and the lack of long-term neurodevelopmental results. Prospective clinical studies including larger sample numbers and evaluating longterm outcomes are needed to further improve prenatal follow-up and prevent neonatal morbidity and mortality.

In conclusion, EP/late birth subgroup and LP group had comparable outcomes regardless of neutrophil count and SGA rate. Close follow up and postponing delivery in appropriate preeclamptic pregnant women could be beneficial for neonates.

\section{REFERENCES}

1. ACOG Committee on Obstetric Practice. ACOG practice bulletin. Diagnosis and management of preeclampsia and eclampsia. Number 33, January 2002. American College of Obstetricians and Gynecologists. Int J Gynaecol Obstet 2002; 77: 67-75.

2. Orhan HG, Ozgüneş H, Beksaç MS. Correlation between plasma malondialdehyde and ceruloplasmin activity values in preeclamptic pregnancies. Clin Biochem 2001; 34: 505-506.

3. Lisonkova S, Sabr Y, Mayer C, Young C, Skoll A, Joseph KS. Maternal morbidity associated with early-onset and late-onset preeclampsia. Obstet Gynecol 2014; 124: 771-781.

4. Ozcimen EE. New approaches for preeclampsia: review of the literature. Gynecol Obstet Reprod Med 2016; 21: 174-176.

5. Valensise H, Vasapollo B, Gagliardi G, Novelli GP. Early and late preeclampsia: two different maternal hemodynamic states in the latent phase of the disease. Hypertension 2008; 52: 873-880.

6. Stergiotou I, Crispi F, Valenzuela-Alcaraz B, Bijnens B, Gratacos E. Patterns of maternal vascular remodeling and responsiveness in early- versus lateonset preeclampsia. Am J Obstet Gynecol 2013; 209: 558.e1-558.e14.

7. Madazli R, Yuksel MA, Imamoglu M, et al. Comparison of clinical and perinatal outcomes in early- and late-onset preeclampsia. Arch Gynecol Obstet 2014; 290: 53-57.

8. Lambert G, Brichant JF, Hartstein G, Bonhomme V, Dewandre PY. Preeclampsia: an update. Acta Anaesthesiol Belg 2014; 65: 137-149. 
9. Norwitz ER, Repke JT. Preeclampsia: Management and prognosis. UpToDate www.uptodate.com (Accessed: 20 April 2018).

10. Duley L. The global impact of pre-eclampsia and eclampsia. Semin Perinatol 2009; 33: 130-137.

11. Kilicci C, Yayla Abide C, Ozkaya E, et al. Confounders for Neonatal Intensive Care Unit admission in neonates of mothers with preeclampsia. Gynecol Obstet Reprod Med 2018; 24: 162-166.

12. Herzog EM, Eggink AJ, Reijnierse A, et al. Impact of early-and late-onset preeclampsia on features of placental and newborn vascular health. Placenta 2017; 49: 72-79.

13. Davis EF, Lazdam M, Lewandowski AJ, et al. Cardiovascular risk factors in children and young adults born to preeclamptic pregnancies: a systematic review. Pediatrics 2012; 129: e1552-e1561.

14. Proytcheva MA. Issues in neonatal cellular analysis. Am J Clin Pathol 2009; 131: 560-573.

15. Elgari MM, Khabour OF, Alhag SM. Correlations between changes in hematological indices of mothers with preeclampsia and umbilical cord blood of newborns. Clin Exp Hypertens 2019; 41: 58-61.

16. Herzog EM, Eggink AJ, van der Zee M, et al. The impact of early- and late-onset preeclampsia on umbilical cord blood cell populations. J Reprod Immunol 2016; 116: 81-85.
17. Ni Y, Cheng W. Comparison of indications of pregnancy termination and prognosis of mothers and neonates in early- and late-onset preeclampsia. Hypertens Pregnancy 2016; 35: 315-322.

18. Iacobelli S, Bonsante F, Robillard PY. Comparison of risk factors and perinatal outcomes in early onset and late onset preeclampsia: a cohort based study in Reunion Island. J Reprod Immunol 2017; 123: 12-16.

19. Nicolaides KH, Bilardo CM, Soothill PW, Campbell $\mathrm{S}$. Absence of end diastolic frequencies in umbilical artery: a sign of fetal hypoxia and acidosis. BMJ 1988; 297: 1026-1027.

20. Manroe BL, Weinberg AG, Rosenfeld CR, Browne $R$. The neonatal blood count in health and disease. I. Reference values for neutrophilic cells. J Pediatr 1979; 95: 89-98.

21. Vogel JP, Chawanpaiboon S, Watananirun $\mathrm{K}$, et al. Global, regional and national levels and trends of preterm birth rates for 1990 to 2014: protocol for development of World Health Organization estimates. Reprod Health 2016; 13: 76.

22. Carbillon L. High performance of maternal characteristics and assessment of uterine artery Doppler waveform for the prediction of early-onset preeclampsia. Am J Obstet Gynecol 2018; 218: 542.

23. Rawlings JS, Pettett G, Wiswell TE, Clapper J. Estimated blood volumes in polycythemic neonates as a function of birth weight. J Pediatr 1982; 101: 594599. 